\title{
Perioperative Problems in Parkinson's Disease and Their Management: Apomorphine with Rectal Domperidone
}

\author{
Néstor Gálvez-Jiménez and Anthony E. Lang
}

\begin{abstract}
Objective: To present guidelines on the use of apomorphine in combination with rectal domperidone in Parkinson's disease (PD) patients undergoing abdominal surgery and to review the perioperative problems encountered in such patients. Background: PD patients undergoing abdominal surgery present a major therapeutic challenge. Because most antiparkinsonian medications must be withheld until the patient is able to resume oral intake, resulting rigidity and akinesia as well as alterations in gastrointestinal motility, respiratory function and swallowing mechanisms predispose these patients to numerous serious postoperative complications. We have found that parenteral apomorphine in combination with rectal domperidone markedly facilitates the care of these difficult patients. Methods: Presentation of two illustrative cases with review of the literature. Results: A standardized protocol using subcutaneous apomorphine and rectal domperidone was used in two PD patients who underwent abdominal surgery. Excellent control of parkinsonian symptomatology was obtained without side effects. The simplicity of the protocol was emphasized in our second patient who required urgent reoperation; the surgery nursing staff was able to restart the apomorphine immediately without having to wait for neurological follow-up assessment. Conclusions: The use of parenteral apomorphine with rectal domperidone in the immediate postoperative period for patients unable to take oral antiparkinson drugs increases patient comfort, facilitates nursing care and may reduce serious postoperative complications.
\end{abstract}

RÉSUMÉ: Difficultés périopératoires dans la maladie de Parkinson: utilisation de l'apomorphine et de la dompéridone rectale. Objectif: Nous présentons des lignes de conduite sur l'utilisation de l'apomorphine combinée à la dompéridone rectale chez les patients parkinsoniens qui subissent une chirurgie abdominale et nous revoyons les problèmes périopératiores rencontrés chez ces patients. Introduction: Les patients parkinsoniens qui subissent une chirurgie abdominale présentent un défi thérapeutique majeur. Comme la plupart des antiparkinsoniens doivent être cessés jusqu'à ce que le patient recommence l'alimentation orale, la rigidité, l'akinésie, les troubles du transit intestinal, de la fonction respiratoire et de la déglutition prédisposent ces patients à de nombreuses complications postopératoires. Nous avons constaté que l'administration d'apomorphine par voie parentérale combinée à la dompéridone par voie rectale facilite beaucoup le soin de ces patients. Méthodes: Nous présentons deux cas comme exemple ainsi qu'une revue de la littérature. Résultats: Nous avons utilisé un protocole standardisé pour l'administration sous-cutanée d'apomorphine et l'administration rectale de dompéridone chez deux patients parkinsoniens qui ont subi une chirurgie abdominale. Un excellent contrôle des symptômes parkinsoniens a ainsi été obtenu, sans effet secondaire. La simplicité du protocole a été mise en évidence dans le second cas lorsque le patient a été soumis d'urgence à une nouvelle intervention chirurgicale. L'équipe de soins infirmiers chirurgicaux a pu réadministrer l'apomorphine immédiatement sans attendre une nouvelle évaluation neurologique. Conclusions: L'administration parentérale d'apomorphine combinée a la dompéridone par voie rectale en postopératoire chez les patients chez qui on ne peut pas administrer la médication antiparkinsonienne par voie orale améliore le confort du patient, facilite les soins infirmiers et peut diminuer les complications postopératoires sérieuses.

Can. J. Neurol. Sci. 1996; 23: 198-203

The perioperative management of patients with Parkinson's disease (PD) has received little attention in the neurological literature. Parkinson's disease affects all ages but particularly the elderly. It has been estimated that PD has a prevalence of 59 to 187 per 100,000 population worldwide ${ }^{l}$ with an annual incidence of 20 per $100,000,2,3$ and in North America $1 \%$ of the population over age 60 is affected by the disease. ${ }^{1,3,4}$ With recent advances in the surgical management of the elderly, ${ }^{5}$ more patients with this disorder are having emergency or elective surgery.

The expected worsening of parkinsonian rigidity and bradykinesia coupled with swallowing difficulties and inability to clear oral and pulmonary secretions make these patients prone to post-surgical complications such as aspiration pneumonia and deep vein thrombosis. Dysfunction of the striated muscle of the upper airway has recently been reported to cause

From The Morton and Gloria Shulman Movement Disorders Centre, The Toronto Hospital, University of Toronto, Toronto.

RECEIVED OCTOBER 4, 1995. ACCEPTED IN FINAL FORM FEBRUARY 20, 1996.

Reprim requests to: Dr. A. E. Lang, The Morton and Gloria Shulman Movement Disorders Centre, The Toronto Hospital, 399 Bathurst Street. MP11-306, Toronto, Ontario, Canada M5T 2S8 
post-operative respiratory failure ${ }^{6}$ In addition, the remote but real possibility for the development of a neuroleptic malignant syndrome (NMS)-like state due to levodopa withdrawal ${ }^{7}$ makes these patients a special surgical challenge. These factors and other difficulties with nursing care become especially important in the post-operative care of patients who cannot take oral medication, since most available antiparkinsonian drugs can only be given by this route.

Apomorphine is a potent combined $\mathrm{D}_{1} / \mathrm{D}_{2}$ dopamine agonist. ${ }^{8}$ It is usually given subcutaneously or intravenously although newer routes of administration are being tested. ${ }^{9,10,11}$ Apomorphine may be used to predict the response of parkinsonian patients to levodopa $a^{8,12,14,15}$ and as adjunctive therapy in patients with severe and unpredictable motor fluctuations. ${ }^{8.16,19}$ Its equivalent potency to levodopa and parenteral formulation make apomorphine an ideal drug for those patients unable to receive oral medications in the immediate post-operative period. Beginning with two case presentations we will review perioperative problems in PD and provide recommendations for the management of patients undergoing abdominal surgery emphasizing the use of subcutaneous apomorphine combined with rectal domperidone.

\section{Patient 1.}

This 69-year-old man with a 23 year history of PD was scheduled for a Billroth II distal subtotal gastrectomy with gastrojejunal anastomosis for adenocarcinoma of the stomach. His PD medications had included different combinations of levodopa/carbidopa, pergolide, amantadine, bromocryptine and selegeline. His clinical course over the years had been characterized by wearing off, on-off, freezing, early morning foot dystonia, peak dose dopa-induced dyskinesias and psychiatric side effects. In his "off" periods, parkinsonian akinesia was extreme, resulting in total dependency in a chair- or bed-bound state. These "off" periods could last anywhere from a few minutes to several hours. He maintained an excellent response to levodopa and during the "on" periods he functioned at a near normal level. Despite many adjustments to his medications the "off" periods remained a major problem a good proportion of the waking hours. At the time of surgery he was taking controlled release levodopa/carbidopa $200 / 50 \mathrm{mg}$ six times daily.

The patient was admitted to the neurology service for management of his PD medications pre- and post-operatively. The necessary dose of apomorphine, was determined using an apomorphine "challenge" test. In preparation for the testing, three days of domperidone treatment with $20 \mathrm{mg}$ orally three times daily was instituted. Twelve hours before testing, all parkinsonian medications were stopped, except for domperidone. The next morning, a baseline Unified Parkinson's Disease Rating Scale (UPDRS ${ }^{20}$ was obtained as well as videotape documentation. His total motor UPDRS score in a practically defined "worst off state", 12 hours without antiparkinson's medication, was 77.5. His scores for rigidity, tremor and bradykinesia were $16.5,10$ and 26 , respectively. Domperidone (Motilium ${ }^{R}$ suppositories, Janssen Pharmaceutica Inc. Emergency Drug Release Program. Bureau of Human Prescription Drugs. Health Protection Branch. Ottawa, Canada) $60 \mathrm{mg}$ in rectal form was given 30 minutes before an initial $1 \mathrm{mg}$ dose of apomorphine subcutaneously. Blood pressure and heart rate changes, nausea and vomiting, flushing, rhinorrhea, yawning, akathisia, drug-induced dyskinesias and changes in the motor sub-section of the UPDRS were carefully documented with each dose. If no response to apomorphine was seen in $\mathbf{3 0}$ minutes the dosage was increased by $1 \mathrm{mg}$ over the last administered dose until a response was obtained or there was the development of intolerable side effects. With $2 \mathrm{mg}$ of apomorphine our patient developed yawning, rhinorrhea, mild choreatic movements of his upper extremities accompanied by dystonic posturing of his neck, and from a bedridden state he was able to walk and move about for approximately 60 minutes at which point akinesia began to return. Higher doses did not result in any greater improvement in his motor response. His total motor UPDRS scores after $2 \mathrm{mg}$ of s.c. apomorphine was 40 , an improvement of $48 \%$. Rigidity, tremor and bradykinesia scores improved by $27 \%, 60 \%$ and $56 \%$ respectively. A second day of testing, following the same protocol, gave similar results. He was started on domperidone $20 \mathrm{mg}$ t.i.d. orally 48 hours before surgery and on the day of surgery a $60 \mathrm{mg}$ suppository was given four times daily with further doses as needed to control the presence of nausea, vomiting or hypotension. Levodopa was continued until the morning of surgery. Apomorphine $2 \mathrm{mg}$ was begun three hours after surgery and was given every three hours afterwards while awake. By the sixth post-operative day his usual levodopa schedule could be reinstituted uneventfully. During the apomorphine therapy period the patient maintained excellent mobility and his parkinsonism did not hamper his post-operative care. No adverse effects were seen, including psychiatric disturbances. The patient was discharged after ten post-operative days. He was seen in follow-up one month after surgery and was doing well.

\section{Patient 2.}

This 55-year-old woman with a 10 year history of Parkinson's disease required surgery for a rectal prolapse. In addition to disabling "onoff" fluctuations and drug-induced dyskinesias, other medical problems included chronic obstructive pulmonary disease (COPD), diverticulosis and depression. At the time of admission she was receiving a total of $800 \mathrm{mg}$ of levodopa/carbidopa per day given in a liquid form every two hours along with $4 \mathrm{mg}$ of pergolide per day. Other medications included theophylline, ipratropium bromide inhaler, salbutamol inhaler and paroxetine.

The patient was admitted to hospital for evaluation and preoperative adjustments of her antiparkinsons medications. Thirty minutes after 30 $\mathrm{mg}$ of oral domperidone, apomorphine $1.5 \mathrm{mg} \mathrm{sc}$ resulted in marked improvement in parkinsonism similar to her response to L-dopa including moderate dyskinesias and a subjective improvement in breathing. No adverse effects were seen.

In the immediate post-operative period the patient received I $\mathrm{mg} \mathrm{sc}$ of apomorphine every hour as needed for 48 hours while in the intensive care unit (total daily dose of $25 \mathrm{mg}$ ), with rectal domperidone 60 mg suppository four times daily. During this time the patient was successfully extubated and nursing care was greatly facilitated by her normal state of mobility resulting from the use of apomorphine. No side effects were seen in the postoperative period. The patient left the intensive care unit after 48 hours of observation and was started on her oral antiparkinson medications. Her post-operative course was complicated by wound infection and dehiscence. The patient required another procedure for debridement and closure of the wound. The ease of the use of the apomorphine protocol was reflected by the ability of the surgery service to restart apomorphine injections in combination with rectal domperidone immediately and proceed to debridement without the delay of waiting for neurological follow-up assessment. One milligram of apomorphine was again given sc hourly while awake as needed (total daily dose of $5 \mathrm{mg}$ ) with $60 \mathrm{mg}$ suppositories of domperidone (three doses over 24 hours) at which point the patient was extubated and able to resume her oral medications. The patient was discharged thirty-eight days later in her usual state of health.

\section{Discussion}

Current advances in surgical techniques and other therapeutic modalities are responsible for an increase in the number of elderly patients undergoing surgical procedures, ${ }^{5}$ including those with PD. Parkinson's disease is characterized by rigidity, bradykinesia/akinesia, tremor and postural instability. ${ }^{21}$ In the post-operative period these symptoms can render the patient immobile adding to their discomfort, hampering nursing care and predisposing to deep vein thrombosis and pulmonary emboli. Other miscellaneous "off-period" symptoms include dyspnea, laryngeal stridor and hypokinesia, rigidity of voluntary respiratory muscles, ${ }^{22}$ as well as a variety of sensory, autonomic, cognitive and psychiatric disturbances which can be as debilitating as the four cardinal symptoms of Parkinson's disease. ${ }^{23}$ 
Surgery may cause various pulmonary abnormalities including changes in lung volume, pattern of ventilation, gas exchange and defense mechanisms ${ }^{24,25}$ due to anaesthesia, tightness of bandages, altered sensorium, post-operative medications and immobilization. Parkinsonian patients may have similar pulmonary abnormalities ${ }^{22}$ even in the absence of a surgical insult. These have been reported in idiopathic Parkinson's disease, ${ }^{26}$ post-encephalitic parkinsonism, ${ }^{27.28}$ the syndrome of familial fatal parkinsonism with hypoventilation and depression ${ }^{29}$ and multiple system atrophy with autonomic failure (Shy-Drager Syndrome).$^{30}$ Specifically in Parkinson's disease, a number of abnormalities of pulmonary function have been described (Table 1). Several of these abnormalities have been correlated with the parkinsonian motor disability ${ }^{31}$ and improvements in various parameters have been documented in response to levodopa therapy (Table 2) probably as a reflection of improvements in rigidity and akinesia. ${ }^{31.33}$ However, fluctuations in respiratory function may occur in a similar fashion to the motor fluctuations seen in the parkinsonian patient on chronic levodopa therapy. ${ }^{26.34 .35}$ Furthermore, superimposed "respiratory dyskinesias" may cause additional breathing disturbances ${ }^{34,35}$ (Table 2).

Table 1: Pulmonary Function Abnormalities Reported in Parkinson's Disease.

Tachypnea with disorganized respiration. ${ }^{52}$

Expiratory flow obstruction ${ }^{31.53}$ similar to COPD due to:

a) increased airway resistance

b) decreased lung elastic recoil.

Reduced respiratory muscle force (fatigue) altering maximal expiratory and inspiratory flow-volume curves ${ }^{31.32}$ increasing oxygen consumption and reducing efficiency of breathing. ${ }^{54}$

Frequent obstructive ${ }^{52}$ and central sleep apnea (the latter might account for higher incidence of death rates during sleep in PD patients). .55

Altered flow-volume loop ("saw-tooth sign") similar to sleep apnea and upper airway obstruction pattern. ${ }^{56.57 .58}$

Irregular or rhythmic involuntary movement of glottic and supraglottic structures. ${ }^{58}$

Severe off-state dystonic stridor (dystonia of pharyngeal muscles). ${ }^{59}$

Pure restrictive pulmonary pattern secondary to rigidity of chest wall and upper airway muscle dysfunction. ${ }^{22}$

"Respiratory apraxia" due to disturbances in voluntary respiratory motor control. ${ }^{22}$

Table 2: Effects of Levodopa on Pulmonary Function in Parkinson's Disease.

Improved forced vital capacity, forced expiratory volume in 1 second, peak (expiratory and inspiratory) flow rates, maximal voluntary ventilation, minute ventilatory volume, total lung capacity, expiratory reserve volume, reversibility of upper airway obstruction and flow volume curves. ${ }^{28,33,60,61}$

Fluctuations in respiratory function similar to motor fluctuations. ${ }^{26.34 .35}$

Respiratory dyskinesias may result in additional restrictive ventilatory defects and shortness of breath. ${ }^{34.35}$
Patients with parkinsonism thus have alterations in pulmonary function due to both the rigidity and akinesia as well as variable, and at times excessive, dopaminergic activity manifested as motor fluctuations and drug-induced dyskinesias. The duration and severity of the underlying parkinsonism as well as the severity of levodopa-induced dyskinesias will greatly influence the urgency with which antiparkinsonian therapy is restarted in the post-operative period. Early ambulation at this time assists in managing airway secretions, avoiding breakdown of the skin, and decreasing the chances of infection and the development of deep vein thrombosis and pulmonary emboli. However, in the case of some procedures (e.g., orthopaedic) early ambulation is not possible and excessive movement, as might occur with levodopa-induced dyskinesias, may compromise the success of the surgery. When early ambulation and improved mobility are desirable, this can be achieved by restarting the patient's regular antiparkinsonian medication early, post-operatively. However, this may not be feasible if the surgery is followed by a period during which oral or nasogastric/duodenal tube administration of drugs is not possible.

Some sources have advocated the use of parenteral route as an alternative to oral antiparkinsonian medications in those undergoing abdominal surgery. Several anticholinergic/antihistaminic drugs are available for parenteral use. Although they may be helpful in selected circumstances their efficacy is limited. In addition, side effects including confusion (especially in the elderly) and further delay in recovery of gastrointestinal function, often contraindicate their use in these patients. The successful use of a continuous intravenous levodopa infusion was reported by Rosin et al. ${ }^{36}$ in a patient with "on-off" fluctuations who underwent abdominal surgery for rectal carcinoma. However this required increasing doses (up to $4 \mathrm{~g} / \mathrm{d}$ ), frequent adjustments in infusion rate, and large amounts of fluids. Although no alterations in heart rate, blood pressure or gastrointestinal function occurred in this patient, the lack of a parenteral peripheral decarboxylase inhibitor (carbidopa or benserazide) raises concerns about these possibilities. Domperidone suppositories, as used in our patients, would probably control peripheral side effects of intravenous levodopa. However, the requirements of large doses of levodopa and fluids would be unchanged.

Lisuride, a water soluble, ergot-derived direct $D_{1}$ and $D_{2}$ receptor agonist,,$^{37}$ can be given subcutaneously or intravenously. However, lisuride is not widely available, will probably never be marketed in North America, and by direct comparison apomorphine has been shown to be more potent and better tolerated. ${ }^{8}$

Apomorphine is a potent dopamine receptor agonist $\mathrm{t}^{8.38 .39}$ which is rapidly absorbed after a single subcutaneous injection, achieving peak plasma concentrations as early as 3 minutes. The onset of clinical effect can begin in 6 minutes and lasts up to 90 minutes. ${ }^{8}$ In patients with late-stage PD and severe motor fluctuations apomorphine can be administered as prn "rescue" therapy or as a continuous subcutaneous infusion by a portable pump. ${ }^{40,41}$ In addition to the "motor" effects, apomorphine also may improve a number of non-motor "off-period" symptoms which could complicate the postoperative state. These include belching and aerophagia, swallowing difficulties, anismus and functional bladder outlet obstruction ${ }^{8.42 .43}$ and a number of autonomic disturbances ${ }^{44,45}$ such as hypersalivation, delayed gastric 
emptying, small intestine motor dysfunction, constipation, sweating, orthostatic hypotension and bladder dysfunction. ${ }^{46}$ These disturbances may predispose the parkinsonian patient to a greater than normal degree of postoperative gastrointestinal motility abnormalities (i.e., constipation, obstipation, paralytic or adynamic ileus, and gastric dilatation). Since these problems resolve spontaneously as the non-parkinsonian patient increases ambulation and oral intake, ${ }^{24,47.48}$ the use of apomorphine in those with Parkinson's disease both for early ambulation and direct GI tract stimulation ${ }^{42,43}$ seems warranted and could hasten surgical recovery.

Broussolle et al. ${ }^{49}$ reported the successful use of continuous subcutaneous apomorphine as replacement therapy for levodopa in four patients with Parkinson's disease undergoing surgery. Since most patients require only short-term therapy in the postoperative period, we favour the use of frequent subcutaneous injections, as applied quite successfully in our patients, rather than the more complicated continuous infusion approach. All of the patients reported by Broussolle et al. tolerated apomorphine without complications. None of them were given a peripheral dopamine antagonist to block side effects of the medication and the authors stated that nausea and vomiting are rare in parkinsonian patients who have previously taken an oral dopaminergic agonist "routinely". However, this has not been our experience with a large number of parkinsonian patients who have received apomorphine for a variety of reasons. Although these "peripheral" dopaminergic side effects ${ }^{15}$ typically decrease with duration of exposure, many patients never develop tachyphylaxis ${ }^{41}$ and most patients requiring perioperative parenteral dopaminergic treatment do not have time to undergo some form of desensitization therapy.

Domperidone, $\mathrm{a}_{2}$ receptor antagonist with poor blood brain barrier penetration, ${ }^{50,51}$ antagonizes "peripheral" dopaminergic side effects without worsening the underlying parkinsonism. ${ }^{50}$ Domperidone is currently available for rectal administration (60 mg suppositories) as an investigational drug. The use of the rectal route makes this drug ideal for parkinsonian patients requiring dopaminergic therapy who cannot take medication by mouth. To our knowledge this formulation has not previously been used in combination with a parenteral dopamine agonist in the perioperative management of severe PD. Although no data are available, we have found that 3 days of oral therapy $(20 \mathrm{mg}$ tid) followed by a $60 \mathrm{mg}$ suppository 3-4 times per day as needed, completely prevents any peripheral side effects from apomorphine.

The perioperative management of the parkinsonian patient requires knowledge of the potential complications of various types of surgery. The neurologist should be able to balance patient comfort against the potential complications of antiparkinsonian therapy. We believe that our current approach as outlined in Table 3 increases patient comfort, facilitates nursing care and can potentially reduce some of the complications seen in the post operative period. The ease and simplicity of this approach is emphasized by experience with our second patient, in whom the surgical and ICU services were able to restart the protocol automatically and uneventfully when the patient required urgent reoperation.
Table 3: Perioperative management of Parkinson's Disease.

1.- Determine the severity of the underlying parkinsonism.

2.- Evaluate the presence of risk factors such as smoking, pulmonary, cardiac or metabolic/endocrine disorders.

3.- Consider the need for pulmonary function testing and arterial blood gases.

4.- Ask to have surgery scheduled in the morning and earlier in the week.

5.- Consider apomorphine therapy if patient will be unable to take medication by mouth or nasogastric tube for some time after surgery and postoperative care and patient comfort would be enhanced by continuing antiparkinsonian therapy during this time: a. Start domperidone orally $20 \mathrm{mg}$ tid 3 days before testing and continue on the day of testing with supplemental doses as necessary. The effectiveness of domperidone suppositories can be tested at this time by using them instead of oral domperidone on the day of apomorphine challenge testing.

b. Apomorphine should be started in a dose of $1-1.5 \mathrm{mg} \mathrm{sc}$. monitoring blood pressure and heart rate, nausea and vomiting, yawning, drug-induced dyskinesias and motor response. Apomorphine should be increased by $1-1.5 \mathrm{mg}$ increments (up to $10-12 \mathrm{mg}$ ) ${ }^{62}$ every 30 minutes until intolerable side effects or best clinical response are obtained.

c. Start oral domperidone 20 tid three days before surgery.

6.- Continue antiparkinsonian medication by mouth with sips of water on the morning of the surgical procedure.

7.- Give domperidone in rectal $(60 \mathrm{mg})$ or oral $(20 \mathrm{mg})$ form on the morning of surgery and continue as soon as possible after surgery in a dose of $60 \mathrm{mg}$ per rectum tid.

8.- After the surgery, as parkinsonian motor or non-motor symptoms interfere with patient care/comfort, begin apomorphine in the previously established dose and continue until the patient can resume oral antiparkinsonian medications. A q 1-3 h prn sc administration in usually sufficient. If predetermined doses of apomorphine commonly fail to give an "on" response, the dose can be increased quickly as per the preoperative testing. Dosages and timing may have to be adjusted if dyskinesias interfere with postoperative care. This approach can also be used in establishing necessary doses for patients who did not undergo preoperative testing (e.g., in the case of emergency surgery).

9.- Traditional therapies (such as benztropine mesylate, $1-2 \mathrm{mg}$ or diphenhydramine $50 \mathrm{mg}$ intravenously or intramuscularly), or lisuride can be used if apomorphine is not available.

10.- Institute such measures as incentive spirometry, breathing exercises, postural drainage and management of airway secretions.

11.- If apomorphine is not given, observe carefully for signs of neuroleptic malignant syndrome (fever, muscle rigidity, autonomic disturbances or altered level of consciousness).

12.- Avoid drugs containing droperidol and fentanyl (as well as other better recognized dopamine antagonists such as neuroleptics and metoclopramide) as they may aggravate the parkinsonism. ${ }^{47}$

\section{ACKNOWLEGEMENT}

This work was partially supported by the National Parkinson Foundation, Miami.

\section{REFERENCES}

1. Tanner CM. Epidemiology of Parkinson's Disease. Neurol Clin 1992; 10(2): 317-329.

2. Rajput AH. Epidemiology of Parkinson's Disease. Can J Neurol Sci 1984; 11: 156-159. 
3. Rajput AH, Offord KP, Beard CM, Kurland LT. Epidemiology of parkinsonism: incidence, classification, and morality. Ann Neurol 1984; 16: 278-282.

4. Marttila RJ. Epidemiology. In: Koller WC, ed. Handbook of Parkinson's Disease. New York: Marcel Dekker, Inc., 1987: 3550 .

5. Edmunds LH, Stephenson LW, Edie RN, Ratcliffe MB. Open-heart surgery in octogenarians. N Engl J Med 1988; 319: 131-136.

6. Easdown LJ, Tessler KJ, Minuk J. Upper airway involvement in Parkinson's disease resulting in postoperative respiratory failure. Can J Anaesth 1995; 42: 344-347.

7. Figa-Talamanca L, Gualandi C, DiMeo L, et al. Hyperthermia after discontinuance of levodopa and bromocriptine therapy: impaired dopamine receptors a possible cause. Neurology 1985; 35: 258261.

8. Colosimo C, Merello M, Albanese A. Clinical usefulness of apomorphine in movement disorders. Clin Neuropharmacol 1994; 17: $243-259$

9. van Laar T, Jansen ENH, Neef C, Danhof M, Roos RAC. Pharmacokinetics and clinical efficacy of rectal apomorphine in patients with Parkinson's Disease: a study of five different suppositories. Mov Disord 1995; 10: 433-439.

10. van Laar T, Jansen ENH, Essink AWG, Neef C. Intranasal apomorphine in parkinsonian "on-off" fluctuations. Arch Neurol 1992; 49: $482-484$

11. Montastruc JL, Rascol O, Senard JM, et al. Sublingual apomorphine in Parkinson's Disease: a clinical and pharmacokinetic study. Clin Neuropharmacol 1991; 14: 432-437.

12. Rascol O, Senard JM, Rascol A, Montastruc JL. Apomorphine test in parkinsonian syndromes. Lancet 1990; 336: 518

13. Hughes AJ, Lees AJ, Stern GM. Apomorphine test to predict dopaminergic responsiveness in parkinsonian syndromes. Lancet 1990; 336: 32-34

14. Bonuccelli U, Piccini P, Del Dotto P, et al. Apomorphine test for dopaminergic responsiveness: a dose assessment study. Mov Disord 1993; 8: 158-164.

15. Hughes AJ, Lees AJ, Stern GM. Apomorphine in the diagnosis and treatment of parkinsonian tremor. Clin Neuropharmacol 1990; 13: 312-317.

16. Chaudhuri KR, Critchley P, Abbott RJ, Pye IF, Millac PAH Subcutaneous apomorphine for on-off oscillations in Parkinson's Disease. Lancet $1988 ; 1260$.

17. de Saint Victor J, Pollak P, Gervason C-L, Pettet J. Levodopainduced diphasic dyskinesias improved by subcutaneous apomorhine. Mov Disord 1992; 7: 283-287.

18. Durif F, Deffond D, Dordain G, Tournilhac M. Apomorphine and diphasic dyskinesia. Clin Neuropharmacol 1994; 17: 99-102.

19. Stibe CMH, Lees AJ, Kempster PA, Stern GM. Subcutaneous apomorphine in parkinsonian on-off oscillations. Lancet 1988; 403406.

20. Fahn S, Elton RL, Members of the UPDRS Development Committee. Unified Parkinson's Disease Rating Scale. In: Fahn $S$, Marsden CD, Goldstein $M$, Calne DB, ed. Recent Development in Parkinson's Disease. Vol. 2 Florham Park, New Jersey: Macmillan, 1987: 153-163.

21. Weiner WJ, Lang AE. Movement Disorders - A Comprehensive Survey. New York: Futura Publishing, 1989.

22. Chokroverty S. The spectrum of ventilatory disturbances in movement disorders. In: Chokroverty S., ed. Movement Disorders. U.S.A. PMA Publishing Corp., 1990: 365-392.

23. Riley DE, Lang AE. The spectrum of levodopa-related fluctuations in Parkinson's disease. Neurology 1993; 43: 1459-1464.

24. Tisi GM. Preoperative evaluation of pulmonary function. Am Rev Respir Dis 1979; $119: 293-310$.

25. Manning FC. Preoperative evaluation of the elderly patient. AFP 1989; 39: 123-128.

26. Ilson J, Braun N, Fahn S. Respiratory fluctuations in Parkinson's Disease. Neurology 1983; 33: 113.

27. Garlind T, Linderholm H. Hypoventilation syndrome in a case of chronic epidemic encephalitis. Acta Med Scand 1958; 333-349.

28. Granerus A, Jagenburg R, Nilsson NJ, Svanborg A. Respiratory disturbance during L-Dopa treatment of Parkinson's Syndrome. Acta Med Scand $1974 ; 195: 39-43$.
29. Purdy A, Hahn A, Barnett HJM, et al. Familial fatal parkinsonism with aveolar hypoventilation and mental depression. Ann Neurol 1979; 6: 523-531.

30. Chokroverty S. Sleep apnoea and respiratory disturbances in multiple system atrophy with autonomic failure. $I n$ : Bannister $\mathrm{R}$. ed. Autonomic Failure. A Textbook of Clinical Disorders of the Autonomic Nervous System. 2nd ed. Oxford: Oxford Medical Publications, 1988: 432-450

31. Neu HC, Connolly JJ, Schwertley FW, Ladwig HA, Brody AW. Obstructive respiratory dysfunction in parkinsonian patients Ann Rev Resp Dis 1967; 95: 33-47.

32. Paulson GD, Tafrate RH. Some "minor" aspects of parkinsonism, especially pulmonary function. Neurology 1970; 20: 14-17.

33. Nakano KK, Bass H, Tyler HR. Levodopa in Parkinson's Disease Arch Intern Med 1972; 130: 346-348.

34. Zupnick HM, Brown LK, Miller A, Moros DA. Respiratory dysfunction due to L-dopa therapy for parkinsonism:diagnosis using serial pulmonary function tests and respiratory inductive plethysmography. Am J Med 1990; 89: 109-114.

35. Weiner WJ, Goetz CG, Nausieda PA, Klawans HL. Respiratory dyskinesias:extra pyramidal dysfunction and dyspnea. Ann Intern Med 1978; 88: 327-331.

36. Rosin AJ, Deveueux D, Eng N, Calne DB. Parkinsonism with "onoff" phenomena - intravenous treatment with levodopa after major abdominal surgery. Arch Neurol 1979; 36: 32-34.

37. Horowski R, Obeso JA. Lisuride: A direct dopamine agonist in the symptomatic treatment of Parkinson's Disease. In: Koller WC Paulson G, ed. Therapy of Parkinson's Disease. 2nd ed. New York: Marcel Dekker, Inc, 1995: 219-248.

38. Strange PG. Dopamine receptors in the basal ganglia: relevance to Parkinson's disease. Mov Disord 1993; 8: 263-270.

39. Strange PG. Multiple dopamine receptors: relevance for neurodegenerative disorders. Biochem Soc Trans 1994; 22: 155-159.

40. Gancher ST, Nutt JG, Woodward WR. Apomorphine infusional therapy in Parkinson's Disease: clinical utility and lack of tolerance. Mov Disord 1995; 10: 37-43.

41. Gancher ST, Woodward WR, Boucher B, Nutt JG. Peripheral pharmacokinetics of apomorphine in humans. Ann Neurol 1989;26: 232-238.

42. Edwards LL, Quigley EMM, Harned RK, Hofman R, Pfeiffer RF. Defecatory function in Parkinson's disease: response to apomorphine. Ann Neurol 1993; 33; 490-493.

43. Mathers SE, Kempster A, Law PJ, et al. Anal sphincter dysfunction in Parkinson's Disease. Arch Neurol 1989; 46: 1061-1064.

44. Edwards LL, Quigley EMM, Pfeiffer RF. Gastrointestinal dysfunction in Parkinson's disease: frequency and pathophysiology. Neurology 1992; 42: 726-732.

45. Rajput AH, Rozdilsky B. Dysautonomia in Parkinsonism: a clinicopathological study. J Neurol Neurosurg Psychiatry 1976; 39: $1092-1100$.

46. Sotolongo JR, Jr. Voiding dysfunction in Parkinson's Disease. Seminar Neurol 1988; 8: 166-169.

47. Corman LC. Neurologic conditions in the perioperative setting. In Kammerer WS, Gross RJ, eds. Medical Consultation - The Internist on Surgical, Obstetric, and Psychiatric Services. Baltimore: Williams and Wilkins, 1990: 470-488.

48. Hayhurst MD. Preoperative pulmonary function testing. Respir Med 1993; 87: 161-163.

49. Broussolle E, Marion MH, Pollak P. Continuous subcutaneous apomorphine as replacement for levodopa in severe parkinsonian patients after surgery. Lancet 1992; 340: 859-860.

50. Parkes JD. Domperidone and Parkinson's Disease. Clin Neuropharmacol 1986; 9: 517-532.

51. Brogden RN, Carmine AA, Heel RC, Speight TM, Avery GS Domperidone - A review of its pharmacological activity, pharmacokinetics and therapeutic efficacy in the symptomatic treatment of chronic dyspepsia and as an antiemetic. Drugs 1982; 24: 360-400.

52. Apps MCP, Sheaff PC, Ingram DA, Kennard C, Empey DW. Respiration and sleep in Parkinson's disease. J Neurol Neurosurg Psychiatry 1985; 48: 1240-1245.

53. Anonymous. The causes of abnormal pulmonary function in Parkinson's Disease. Am Rev Respir Dis 1972; 105: 382-387.

54. Tzelepis GE, McCool FD, Friedman JH, Hoppin FG. Respiratory muscle dysfunction in Parkinson's Disease. Am Rev Respir Dis $1988 ; 138: 266-271$ 
55. Hardie RJ, Efthimiou J, Stern GM. Respiration and sleep in Parkinson's disease. J Neurol Neurosurg Psychiatry 1986; 50: 1326.

56. Bogaard JM, Hovestadt A, Meerwald J, v.d.Meche FGA, Stigt J. Flow-volume curves in Parkinson's Disease. Bulletin Europeen de Physiopathologie Respiratoire 1987; 23: 4175.

57. Schiffman PL. A “saw-tooth" pattern in Parkinson's Disease. Chest 1985; 87: 124-126.

58. Vincken WG, Gauthier S, Dollfuss RE, et al. Involvement of upperairway muscles in extrapyramidal disorders - a cause of airflow limitation. N Engl J Med 1984; 311: 438-442.
59. Corbin DOC, Williams AC. Stridor during dystonic phases of Parkinson's disease. J Neurol Neurosurg Psychiatry 1987; 50: 821822.

60. Vincken WG, Darauay CM, Cosio MG. Reversibility of upper airway obstruction after levodopa therapy in Parkinson's Disease. Chest 1989; 96: 210-212.

61. De Bruin PFC, De Bruin VMS, Lees AJ, Pride NB. Effects of treatment on airway dynamics and respiratory muscle strength in Parkinson's Disease. Am Rev Respir Dis 1993; 148: 1576-1580.

62. D'Costa DF, Abbott RJ, Pye IF, Millac PAH. The apomorphine test in Parkinsonian syndromes. J Neurol Neurosurg Psychiatry 1991; 54: 870-872. 